\title{
Twenty Years, Twenty Publications and could have been More: Revisiting Research Collaboration with Professor Bidyut Kanti Datta
}

\author{
Satyajit D. Sarker ${ }^{1}$, Lutfun Nahar ${ }^{1}$, Sitesh C. Bachar ${ }^{2}$ \\ and Mohammad A. Rashid ${ }^{2}$ \\ ${ }^{1}$ Centre for Natural Products Discovery (CNPD), School of Pharmacy and Biomolecular Sciences, Liverpool \\ John Moores University, James Parsons Building, Byrom Street, Liverpool L3 3AF, United Kingdom. \\ ${ }^{2}$ Department of Pharmacy, University of Dhaka, Dhaka-1000, Bangladesh. \\ ${ }^{3}$ Department of Pharmaceutical Chemistry, University of Dhaka, Dhaka-1000, Bangladesh.
}

(Received: September 15, 2020; Accepted: November 17, 2020; Published (web): December 10, 2020)

\begin{abstract}
Professor Bidyut Kanti Datta, a renowned professor of the Department of Pharmacy, Faculty of Pharmacy, University of Dhaka, died at the age of 73 on Friday 11 September 2020 in Canada (Canadian time 7.10 am and BD time $5.10 \mathrm{pm}$ ), as a consequence of COVID-19 infection followed by pneumonia. This article is a brief review of his research work where the authors of this article are immensely proud to be associated with. Prof Datta published more than 60 research articles in reputed journals, and the lead author (SDS) of this article, one of his former students from the University of Dhaka, is a co-author of 20 of those publications. These 20 publications resulted from a long-standing research collaboration that spanned over two decades, especially research involving various Bangladeshi species of the genus Polygonum L. of the family, Polygonaceae, and they demonstrate the breadth and depth of research activities that Prof Datta was involved in, and his long-standing commitment to research that underpinned and enriched his teaching offerings to hundreds of students he taught in higher education sector in Bangladesh.
\end{abstract}

Key words: Bidyut Kanti Datta, Polygonum, Polygonaceae, phytochemistry, bioactivity, sesquiterpenes, flavonoids and NMR

\section{INTRODUCTION}

By the time this article will be submitted to the journal for publication, the sad news of Prof Bidyut Kanti Datta's eternal departure will be known to the readers, especially to those who were closely associated with this great teacher and incredible human being, who led his life with utmost integrity and absolute honesty. According to the press release, Professor Bidyut Kanti Datta, a renowned professor of the Department of Pharmacy, Faculty of Pharmacy, University of Dhaka, died at the age of 74 on Friday 11 September 2020 in Canada (Canadian time 7.10 am and $\mathrm{BD}$ time $5.10 \mathrm{pm}$ ), as a consequence of COVID-19 infection followed by pneumonia. ${ }^{1}$ Prof Datta's biography including his

Correspondence to: Satyajit D. Sarker

Email: S.Sarker@1jmu.ac.uk

Dhaka Univ. J. Pharm. Sci. 19(2): 97-103, 2020 (December) DOI: https://doi.org/10.3329/dujps.v19i2.50623

long and extraordinary service to higher education in Bangladesh, particularly in Pharmacy, starting as a Lecturer, then as a Professor and also in various leading academic roles as a Head of Department and Dean, can be available through various relevant publications and websites, as well as the press release. ${ }^{1}$ This article is definitely not about his life and work in their entirety, but a brief review of his research work where the authors are immensely proud to be associated with. Prof Datta published more than 60 research articles in reputed journals, and the lead author (SDS) of this article, one of his students from the University of Dhaka, is a co-author of 20 of those publications. These 20 publications ${ }^{2-21}$ resulted from a long-standing research collaboration that spanned over two decades, especially research involving various Bangladeshi species of the genus Polygonum L. of the family, Polygonaceae. Prof 
Datta, despite his retirement, harboured his passion for phytochemical research, and continued to be associated with research activities through his students and colleagues, and one can only assume that there would have been many more co-authored publications with him, if he was still with us.

Phytochemistry. Prof Datta's major contribution in the field of phytochemistry incorporates his work with the Polygonum genus, which also was the topic of his $\mathrm{PhD}$ research, and later, the topic of his student projects. Among the compounds that he isolated and identified from this genus mainly belong to the phytochemical classes of flavonoids and sesquiterpenes, and many of those were new compounds. ${ }^{2-21}$ The very first joint publication, where SDS was a co-author, was published in the leading journal, Phytochemistry, ${ }^{2}$ which described the isolation and identification of two new compounds, viscosumic acid (21) and a feruloyl derivative of quercetin galactoside (9), together with a known flavonoid, 3'5-dihydroxy-3,4',5',7-tetramethoxyflavone (1) from Polygonum viscosum BuchHam. (Figures 1 and 2). It is noteworthy that this piece of work involved preparative reversed-phase HPLC-aided isolation of compounds, and a detailed 1D and 2D NMR techniques were applied to deduce the structures of these compounds; in addition to NOESY, a relatively new technique, GOESY was used to establish relative stereochemistry at the chiral centres present in the sesquiterpene acid (21). In the same year, two other acylated flavonoids, quercetin 3-O-(6'"-caffeoyl)- $\beta$-D-galactopyranoside (7) and quercetin 3-O-(6"'-galloyl)- $\beta$-D-galactopyranoside (8), similar to 9, were reported from the methanol extract of the same plant (Figure 1). ${ }^{3,4}$

In the following year, a reversed-phase HPLC based analysis of the methanol extract of $P$. viscosum afforded a new sesquiterpene acid, viscozulenic acid (17) (Figure 2). ${ }^{5}$ In continuation of phytochemical work with this species, collected from the Hill Tracts of Chittagong, provided another new sesquiterpene, viscoazucine (15) (Figure 2), together with a known flavone, 3',5,7-trihydroxy-3,4',5'-trimethoxyflavone (3) (Figure 1). ${ }^{6} \mathrm{~A}$ year later, two other novel sesquiterpenes, viscoazulone (19) and viscoazusone (20) were reported from this plant (Figure 2). ${ }^{7}$ Moving on to another species, P. stagninum Buch.Ham. ex Meissn., phytochemical investigation of the aerial parts afforded known flavonoids, hypersoside (5), isoquerctitrin (6), onysilin (13) and rhamnocitrin (2) (Figure 1), and cinnamic acid derivatives, cinnamic acid (23) and 4-methoxy-cinnamic acid (24) (Figure 3) in the same year. ${ }^{8}$ Possible chemotaxonomic implication of these isolates within the genus Polygonum and also in the family Polygonaceae was also highlighted in this report.

A few years later, moving back to $P$. viscosum, but not the methanol exact this time, phytochemical analysis of the chloroform extract of the aerial parts resulted in the isolation and identification of three new sesquiterpenes, polygosumic acid (14), viscozulenic acid methyl ester (18) and viscoazucinic acid (16) (Figure 2) with promising antibacterial activity. ${ }^{9}$ In 2010, phytochemical investigation of another species of the genus, Polygonum, $P$. flaccidum Meissn. provided $\square$-santalone (25) as the major bioactive compound in the aerial parts of this plant (Figure 3). ${ }^{10}$ Later, viscozulenic acid (17), previously reported from $P$. viscosum, (Figure 2), and acetophenone (22) and sitosterone (26) (Figure 3) were isolated from $P$. barbatum (L.) Hara var. barbata. $^{11}$

Moving away from the genus Polygonum, the collaborative work on Nicotiana plumbaginifolia, afforded several highly oxygenated rare flavonoids, 3,3',5,6,7,8-hexamethoxy-4',5'-methylenedioxyflavone (10), 3,3',4',5',5,6,7,8-octamethoxyflavone (12), 6,7,4',5'-dimethylenedioxy-3,5,3'-trimethoxyflavone (4) and 3,3',4',5,5',8-hexamethoxy-6,7-methylenedioxyflavone (11) from the leaves of this plant (Figure 1). ${ }^{12}$ It can be mentioned here that the distribution of these flavonoids appears to be restricted within the genera Polygonum and Murraya.

Synthesis. Although the main collaborative activity was in the area of phytochemistry and phytotherapy, collaboration was also extended to synthetic medicinal chemistry area, where the key 
<smiles></smiles>

3', 5-Dihydroxy-3,4',5',7-tetramethoxyflavone (1) $\mathrm{R}=\mathrm{R}$ ' = R'", = Me; R' = OH; R", = OMe

Rhamnocitrin (2) $\mathrm{R}=\mathrm{R}$ ', $=\mathrm{H}$; R'=Me; R"'=R"," = H 3',5,7-Trihydroxy-3,4',5'-trimethoxyflavone (3) R' = H; $\mathrm{R} "$ = OH; R = R'”, = Me; R",' = OMe<smiles>COc1cc(-c2oc3cc4c(c(OC)c3c(=O)c2OC)OCO4)cc2c1OCO2</smiles>

6,7,4',5'-Dimethylenedioxy-3,5,3'-trimethoxyflavone (4)<smiles></smiles>

$$
\begin{aligned}
& \text { Hyperoside (5) } R=\beta \text {-D-galactopyranosyl } \\
& \text { Isoquercitrin (6) } R=\beta \text {-D-glucopyranosyl }
\end{aligned}
$$

Quercetin 3-O-(6"'-caffeoyl)- $\beta$-D-galactopyranoside (7) $\mathrm{R}=$ (6"'-caffeoyl)- $\beta$-D-galactopyranosyl Quercetin 3-O-(6' '-galloyl)- $\beta$-D-galactopyranoside (8) $\mathrm{R}=$ (6" '-galloyl)- $\beta$-D-galactopyranosyl Quercetin 3-O-(6"'-feruloyl)- $\beta$-D-galactopyranoside (9) R = (6"'-feruloyl)- $\beta$-D-galactopyranosyl<smiles>COc1cc(-c2oc3c(OC)c(OC)c(OC)c(OC)c3c(=O)c2OC)cc2c1OCO2</smiles>

3,3',5,6,7,8-Hexamethoxy-4',5'-methylenedioxy-flavone (10)<smiles>COc1cc(-c2oc3c(OC)c(OC)c(OC)c(OC)c3c(=O)c2OC)cc(OC)c1OC</smiles>

$3,3^{\prime}, 4^{\prime}, 5^{\prime}, 5,6,7,8$-Octamethoxyflavone (12)<smiles>COc1cc(-c2oc3c(O)c4c(c(OC)c3c(=O)c2OC)OCO4)cc(OC)c1OC</smiles>

3,3',4',5,5',8-Hexamethoxy-6,7methylenedioxyflavone (11)<smiles>COc1cc2c(c(O)c1OC)C(=O)CC(c1ccccc1)O2</smiles>

Onysilin (13)

Figure 1. Structures of flavonoids isolated from Polygonum species and Nicotiana plumbaginifolia. 


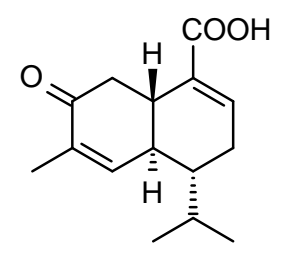

Polygosumic acid (14)

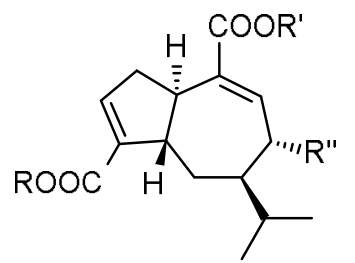

Viscoazucine (15) $\mathrm{R}=\mathrm{R}$ ' = Me; R' = H

Viscoazucinic acid (16) $\mathrm{R}=\mathrm{M} ; \mathrm{R}^{\prime}=\mathrm{R}^{\prime}$ ' $=\mathrm{Me}$

Viscozulenic acid (17) $\mathrm{R}=\mathrm{H} ; \mathrm{R}^{\prime}=\mathrm{Me} ; \mathrm{R}^{\prime}=\mathrm{OH}$

Viscozulenic acid methyl ester (18) $\mathrm{R}=\mathrm{R}$ ' $=\mathrm{Me} ; \mathrm{R}^{\prime \prime}=\mathrm{OH}$

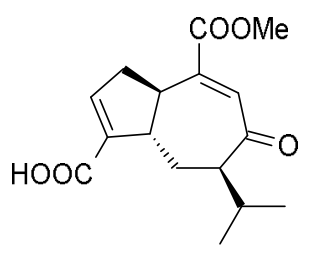

Viscoazusone (20)

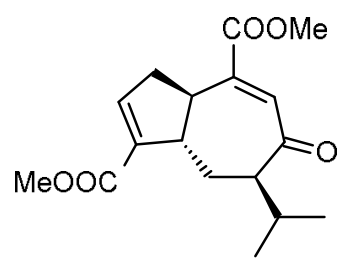

Viscoazulone (19)

Figure 2. Structures of sesquiterpenes isolated from Polygonum species.<smiles>CC(=O)c1ccccc1</smiles>

Acetophenone (22)

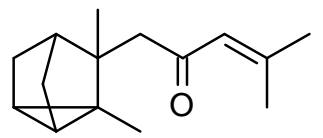

$\alpha$-Santalone (25)<smiles>[R]c1ccc(/C=C/C(=O)O)cc1</smiles>

Cinnamic acid (23) $\mathrm{R}=\mathrm{H}$

4-Methoxy-cinnamic acid (24) $\mathrm{R}=\mathrm{OMe}$

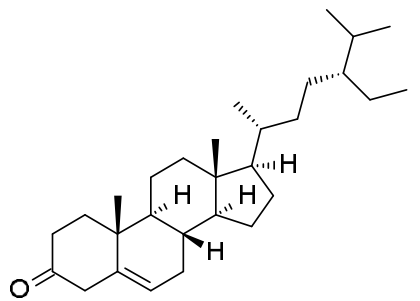

Sitosterone (26)

Figure 3. Structures of miscellaneous compounds isolated from the Polygonum species. 
role was played by Prof Sitesh Chandra Bachar, the immediate past Head of the Department of Pharmacy, Dhaka University, and Prof Datta was one of the major collaborators. The first publication from this collaborative work was published in 2009, and it described the total synthesis and analgesic activity of 6-fluoroindan-1-acetic acid and its 3-oxo derivatives. ${ }^{13}$ In continuation with the same theme, further anti-inflammatory indan derivatives were synthesized, which include 5,6-dichloroindan-1-acids and their tetrazolyl derivatives. ${ }^{14}$

Bioactivity. Collaborative bioactivity studies, mainly but not exclusively, on the analgesic and antiinflammatory activities, were with the crude extracts and isolated compounds from the genera Polygonum,,${ }^{11,-21}$ Phyllanthus ${ }^{15}$ and Nicotiana,${ }^{16}$ but also included several synthetic indan derivatives. ${ }^{13,14}$ The most recent bioactivity study was on the isolated rare polymethoxyflavones (Figure 1) from the Nicotiana plumbaginifolia Viv. of the family Solanaceae, where it was demonstrated that these flavonoids possess significant antinociceptive property, as evident in the acetic-acid-induced writhing, hot plate, tail immersion, formalin and carrageenan-induced paw edema tests. ${ }^{16}$ These compounds could also display neuropharmacological effects in mice. The level of activity among these flavonoids was quite variable, and in all occasions, the activity was dose dependent.

The analgesic and anti-inflammatory activities of the extracts of Phyllanthis reticulatus Poir. were studied in mice and the extracts were found to be active at the oral doses of $150-300 \mathrm{mg} / \mathrm{kg} .{ }^{15}$ However, the activity was not tested with any isolated compounds from this plant.

Most of the isolated compounds from Polygonum species were tested for various activities. Acetophenone (22), sitosterone (26) and viscoazulenic acid (17), isolated from Polygonum barbatum (L.) Hara var. barbata, were tested for free-radical-scavenging activity using the DPPH (2,2diphenyl-1-picryl-hydrazyl) assay. ${ }^{11}$ However, none of the compounds showed any noticeable activity. Earlier, the extracts of $P$. barbatum and P. stagninum were assessed for potential antitumour activity using a simple potato disc assay, and the $n$-hexane and ethyl acetate extracts of both plants were found to possess this activity, but not the methanol extracts, implying that the active components in these extracts were nonpolar or medium polarity compounds. ${ }^{17}$ Mazid et al. ${ }^{18}$ also tested the analgesic and antiinflammatory potential of the extracts of the aerial parts of P. stagninum Buch.-Ham. ex Meissn. In the acetic-acid-induced writhing test, the extracts showed dose dependent analgesic activity, with ethyl acetate extract being the most active extract at a dose of 400 $\mathrm{mg} / \mathrm{kg}$ body weight. On the other hand, the $n$-hexane extract was found to be most active as an antiinflammatory agent, better than the conventional antiinflammatory agent phenylbutazone. Similarly, the extracts of Polygonum barbatum var. barbata were assessed for potential analgesic, anti-inflammatory and diuretic properties in mice model. ${ }^{19}$ The result was promising; the extracts were active, especially the analgesic activity of the petroleum ether extract was better than the positive control aminopyrine. All extracts increased urine volume in a dose dependent manner with ethyl acetate extract being the most active one.

$\alpha$-Santalone (25) was isolated as an analgesic compound present in the aerial parts of $P$. flaccidum Meissn. as a result of the acetic-acid-induced writhing assay, and the compound was also tested for diuretic activity using the Lipschitz test. ${ }^{10}$ The sesquiterpenes, viscosumic acid (21), viscozulenic acid (17), viscoazucine (15) and viscoazulone (19) as well as the flavonoid, quercetin 3-O-(6"'-feruloyl)galactoside (9), isolated from $P$. viscosum were tested for analgesic, anti-inflammatory and CNS depressant activities in animal models. ${ }^{20}$ All compounds displayed CNS depressant property in the open field test, whist except viscoazulone (19) all other compounds showed analgesic activity in the Eddy's hot plate test. All but viscoazucine (15) and the flavonoid (9) were found to possess antiinflammatory property as evident in the carrageenaninduced rat paw edema experiment. In the same year, these compounds were also tested for their anticholinergic, cytotoxic and anti-HIV potential. ${ }^{21}$ 
The flavonoid glycoside (9) showed considerable cytotoxicity against the ovarian cell line (OVCAR-3) with an $\mathrm{IC}_{50}$ value of $13.33 \mu \mathrm{g} / \mathrm{ml}$ ), anti-HIV activity $\left(\mathrm{IC}_{50}=25.61 \mu \mathrm{g} / \mathrm{ml}\right)$ and mild anticholinergic activity. Among the sesquiterpenes only viscoazulone (19) showed anti-HIV activity with an $\mathrm{IC}_{50}$ value of $33.13 \mu \mathrm{g} / \mathrm{ml}$ ). Polygosumic acid (14), isolated from $P$. viscosum was shown to possess antibacterial activity, and found to inhibit the growth of penicillinresistant Escherichia coli and methicillin-resistant Staphylococcus aureus (MRSA) in the resazurin assay with MIC ranging between 0.05 and 0.10 $\mathrm{mg} / \mathrm{mL}){ }^{9}$ Viscozulenic acid methyl ether (18) and viscoazucinic acid (16) showed low levels of antibacterial activity.

The analgesic and anti-inflammatory activity of indan derivatives were evaluated by the acetic-acidinduced writhing in Swiss albino mice and the carrageenan-induced rat paw edema models, respectively. ${ }^{13,14}$ Most of these indan derivatives showed activity that was comparable to positive controls, e.g., phenylbutazone, indomethacin and aminopyrine.

\section{CONCLUSION}

The 20 publications of the lead author of this article, published over 20 years, in collaboration with Professor B K Datta cover various aspects of phytochemical research encompassing phytochemistry and phytotherapy, and also synthetic medicinal chemistry and demonstrate the breadth and depth of research activities that Prof Datta was involved in, and his long-standing commitment to research that underpinned and enriched his teaching offerings to hundreds of students he taught in higher education sector in Bangladesh.

\section{ACKNOWLEDGEMENTS}

We gratefully acknowledge the contributions from all co-authors in our joint publications with Prof Bidyut Kanti Datta, including Abdu A. Auzi, S. A. M. Khairul Bashar, A. K. Azad Chaudhury, Sharmistha Das, Sadhan Kumar Datta, Simon Gibbons, Alexander I. Gray, Chaudhury Mahmood
Hasan, Syed A. Hossein, T H Khan, Joydeb Kumar Kundu, M. Mehedi Masud, Md Abdul Mazid, Robert J Nash, Rajib K. Paul, M. Mukhlesur Rahman, M. Shafikur Rahman, Suvash C. Roy, Md Shafiullah Shajib, Md Hossain Sohrab and Hasina Yasmin.

\section{REFERENCES}

1. Bachar, S. C. and Rahman, S. M. A. 2020. Press release on 11 September 2020, Department of Pharmacy, Faculty of Pharmacy, University of Dhaka.

2. Datta, B. K., Datta, S. K., Rashid, M. A., Nash, R. J. and Sarker, S. D. 2000. A sesquiterpene acid and flavonoids from Polygonum viscosum. Phytochemistry 54, 201-205.

3. Datta, B. K., Datta, S. K. and Sarker, S. D. 2000. Quercetin 3-O-(6"'-caffeoyl)- $\square$-D-galactopyranoside from Polygonum viscosum. Fitoterapia 71, 459-460.

4. Datta, B. K., Datta, S. K. and Sarker, S. D. 2000. Quercetin 3-O-(6"-galloyl)- $\square$-D-galactopyranoside from Polygonum viscosum (Polygonaceae). Biochem. Syst. Ecol. 28, 805-807.

5. Datta, B. K., Rashid, M. A., Datta, S. K. and Sarker, S. D. 2001. Viscozulenic acid: A novel sesquiterpene acid from Polygonum viscosum. Pharmaceut. Biol. 39, 198-201.

6. Datta, B. K., Rashid, M. A., Kundu, J. K., Rouf, A. S. S., Sarker, S. D. and Datta, S. K. 2001. Isolation and structure elucidation of viscoazucine, a novel sesquiterpene from Polygonum viscosum. Pharmazie 56, 578-579.

7. Datta, B. K., Datta, S. K., Rashid, M. A., Kundu, J. K., Hasan, C. M. and Sarker, S. D. 2002. Further sesquiterpenes from Polygonum viscosum (Polygonaceae). Nat. Prod. Lett. 16, 143-148.

8. Datta, B. K., Datta, S. K., Rashid, M. A. and Sarker, S. D. 2002. Flavonoids from Polygonum stagninum (Polygonaceae). Biochem. Syst. Ecol. 30, 693-696.

9. Datta, B. K., Rahman, M. M., Gray, A. I., Nahar, L., Hossein, S. A., Auzi, A. A. and Sarker, S. D. 2007. Polygosumic acid, a new cadinane sesquiterpene from Polygonum viscosum, inhibits the growth of drug-resistant Escherichia coli and Staphylococcus aureus (MRSA) in vitro. J. Nat. Med. 61, 391-396.

10. Mazid, M. A., Datta, B. K., Nahar, L., Rashid, M. A., Bachar, S. C., Bashar, A. A. M. K. and Sarker, S. D. 2010. Analgesic and diuretic properties of alpha-santalone from Polygonum flaccidum. Phytother. Res. 25, 1084-1087.

11. Mazid, M. A., Datta, B. K., Nahar, L., Bashar, S. A. M. K., Bachar, S. C. and Sarker, S. D. 2011. Phytochemical studies on Polygonum barbatum (L.) Hara var. barbata (Polygonaceae). 2011. Rec. Nat. Prod. 5, 143-146.

12. Shajib, M. S., Datta, B. K., Sohrab, M. H., Rashid, M. A., Nahar, L. and Sarker, S. D. 2017. Highly oxygenated flavonoids from the leaves of Nicotiana plumbaginifolia (Solanaceae). Rec. Nat. Prod. 11, 568-572. 
13. Yasmin, H., Das, S., Nahar, L., Masur, M. M., Rahman, M S., Roy, S. C., Rahman, M. M., Gibbons, S., Kundu, J. K., Datta, B. K. and Sarker, S. D. 2009. Total synthesis and analgesic activity of 6-fluoroindan-1-acetic acid and its 3-oxo derivative. Med. Chem. 5, 468-473.

14. Pal, R. K., Yasmin, H., Nahar, L., Datta, B. K., Chowdhury, A. K. A., Kundu, J. K., Bachar, S. C. and Sarker, S. D. 2012. Synthesis of 5,6-dichloroindan-1-acetic acids and their tetrazolyl derivatives as analgesic and anti-inflammatory agents. Med. Chem. 8, 874-882.

15. Saha, A., Masud, M. A., Bachar, S. C., Kundu, J. K., Datta, B. K., Nahar, L. and Sarker, S. D. 2007. The analgesic and anti-inflammatory activities of the extracts of Phyllanthus reticulatus. Pharmaceut. Biol. 45, 355-359.

16. Shajib, M. S., Rashid, R. B., Ming, L. C., Islam, S., Sarker, M. M. R., Nahar, L., Sarker, S. D., Datta, B. K. and Rashid, M. A. 2018. Polymethoxyflavones from Nicotiana plumbaginifolia (Solanaceae) exert antinociceptive and neuropharmacological effects in mice. Front. Pharmacol. 9, Article number: 85, DOI: 10.3389/fphar.2018.00085.

17. Mazid, M. A., Nahar, L., Datta, B. K., Bashar, S. A. M. K. and Sarker, S. D. 2011. Potential antitumour activity of two Polygonum species. Arch. Biol. Sci. 63, 465-468.
18. Mazid, M. A., Datta, B. K., Bachar, S. C., Bashar, S. A. M. K., Nahar, L. and Sarker, S. D. 2010. Analgesic and antiinflammatory activities of Polygonum stagninum. Pharmaceut. Biol. 48, 770-774.

19. Mazid, M. A., Datta, B. K., Nahar, L., Bashar, S. A. M. K., Bachar, S. C. and Sarker, S. D. 2009. Antinociceptive, antiinflammatory and diuretic properties of Polygonum barbatum (P.) Hara var. barbata. Brazilian J. Pharmacog. 19, 749-754.

20. Datta, B. K., Datta, S. K., Chowdhury, M. M., Khan, T. H., Kundu, J. K., Rashid, M. A., Nahar, L. and Sarker, S. D. 2004. Analgesic, anti-inflammatory and CNS depressant activities of sesquiterpenes and a flavonoid glycoside from Polygonum viscosum. Pharmazie 59, 222-225.

21. Datta, B. K., Datta, S. K., Khan, T. H., Kundu, J. K., Rashid, M. A., Nahar, L. and Sarker, S. D. 2004. Anticholinergic, cytotoxic and anti-HIV activities of sesquiterpenes and a flavonoid glycoside from the aerial parts of Polygonum viscosum. Pharmaceut. Biol. 42, 18-23. 